\title{
Current Practice in Low Vision Rehabilitation of Age-related Macular Degeneration and Usefulness of Virtual Reality as a Rehabilitation Tool
}

Marine Raphanel $^{1 *}$, Gabrielle Shaughness ${ }^{2}$, William H. Seiple ${ }^{1,3}$ and Angelo Arleo ${ }^{1}$

${ }^{1}$ Sorbonne Université, INSERM, CNRS, Institut de la Vision, 17 rue Moreau, F-75012 Paris, France

${ }^{2}$ University of Michigan Medical School, 1000 Wall Street, Ann Arbor, MI 48105, USA

${ }^{3}$ Lighthouse International, Arlene R. Gordon Research Institute, 111 E 59th St, New York NY 10022-1202, USA

\begin{abstract}
Purpose: This study surveys current low vision rehabilitation practice methodologies among French practitioners and it describes their opinions about the utility of using virtual reality as a tool for low vision rehabilitation training in patients with age-related macular degeneration.

Methods: An online questionnaire was distributed between October 2017 and February 2018. 471 orthoptists (110 students and 361 graduates) responded to the survey. Questions concerned the orthoptist's educational and demographic background, extent of training in virtual reality as a reeducation tool, and mode of practice including frequency of patient visits, goals, and methods of rehabilitation training.

Results: Out of 361 practicing orthoptists, $47.75 \%$ were low vision rehabilitation providers, and $52.25 \%$ were not. A provider's likelihood of using low vision rehabilitation immediately after graduating from university was positively correlated to his confidence in the training he had received. Most respondents were receptive to using virtual reality as a reeducation tool.

Conclusions: Analysis of current low vision rehabilitation practice demonstrates no standardization of treatment protocols among providers. Although orthoptists overall acknowledge the benefits of virtual reality as a rehabilitation tool, orthoptist curriculum varies greatly across universities, which thus affects a provider's likelihood of offering low vision rehabilitation. Moreover, this lack of standardization is a problem worldwide, which suggests a need for better clinical guidelines in low vision rehabilitation practice.
\end{abstract}

Keywords: Low vision rehabilitation; Age-related macular degeneration; Training; Visual impairment; Virtual reality

\section{Introduction}

Age-related Macular Degeneration (AMD) affects the central retina, resulting in a progressive loss of central vision. As the leading cause of acquired visual impairment in the Western world, AMD is responsible for $8.7 \%$ of all blindness worldwide. In individuals aged 65 to 75 years, AMD prevalence ranges between $9 \%-25 \%$, and over $80 \%$ of those affected become legally blind after age 70 [1-8]. In France, AMD affects $8 \%$ of the population, and its frequency increases with age: $1 \%$ of people aged 50 to 55 years, $10 \%$ of those 65 to 75 years, and $25 \%$ to $30 \%$ of persons aged over 75 suffer from AMD [1,6,9-11].

Although treatment options exist to slow the progression of exudative (wet) AMD, currently there are no preventive or curative options for active pathology. As individuals lose their central vision and the ability to discriminate between fine spatial details, they become less autonomous in performing basic activities of daily living (ADLs, e.g., walking, feeding, dressing) as well as instrumental activities of daily living (IADLs, e.g., taking medications, independent mobility, managing money). This predisposes them to low self-esteem and it is correlated with a three times greater risk of developing depression [3,5-10]. Additionally, AMD patients are twice as likely to fall and four times more likely to fracture a hip $[4,6,7,9,10-18]$. Significant social and economic ramifications will thus ensue as the proportion of older adults in the general population continues to rise [1,19-21].

Because AMD is among the most common etiologies of vision loss, this disease accounts for a majority of patients enrolled in low vision rehabilitation [22]. By helping the patient adapt to, and optimize the use of, his residual visual function, this therapy increases autonomy and improves quality of life in people with vision loss. Current recommendations for the clinical management of patients with AMD, as outlined by the French High Health Authority, begin with pharmaceutical or surgical treatment, followed by referral to a low vision provider [23]. However, in actual clinical practice, only $10 \%$ -
$15 \%$ of French visually impaired patients are referred to a low vision professional, while it is estimated that $90 \%$ of patients could benefit from this support [11]. The underuse of low vision rehabilitation is echoed globally, as for example, in India, only $30 \%$ of eligible patients are referred for low vision rehabilitation [24].

Furthermore, practices are not standardized among low vision providers, both in France and world-wide [25-29]. For example in the UK, there is no consistency between services that eye care professionals feel are available and reports by visually impaired patients of the service they receive [26]. In Canada, each Province or Territory is responsible for its own healthcare administration. This has resulted in discrepancies between urban and rural area funding for low vision rehabilitation with neither a published rehabilitation model nor a consistent referral system between regions [30,31]. A lack of consensus on terminology and management criteria among low vision practitioners is also described in the United States, which makes it difficult to even ascertain current practices [28]. Globally, practitioners tend to use empirical rather than evidence-based rehabilitation protocols and there is little agreement about how best to measure low-vision service outcomes [11,25]. The need to study and improve current methodologies is echoed by Markowitz et al. who conclude in a 2016 review of current global low vision practices that "the main challenge to low vision rehabilitation practice at the

*Corresponding author: Marine Raphanel, Sorbonne Université INSERM, CNRS, Institut de la Vision, 17 rue Moreau, F-75012 Paris, France, E-mail: marine.raphanel-redon@inserm.fr

Received August 06, 2018; Accepted September 05, 2018; Published September 10, 2018

Citation: Raphanel M, Shaughness G, Seiple WH, Arleo A (2018) Current Practice in Low Vision Rehabilitation of Age-related Macular Degeneration and Usefulness of Virtual Reality as a Rehabilitation Tool. Aging Sci 6: 194. doi: 10.4172/2329. 8847.1000194

Copyright: (c) 2018 Raphanel M, et al. This is an open-access article distributed under the terms of the Creative Commons Attribution License, which permits unrestricted use, distribution, and reproduction in any medium, provided the origina author and source are credited. 
international level is the absence of standards for definitions of low vision rehabilitation and delivery models for low vision rehabilitation service" [29].

In this study, we investigated demographics and practice patterns of low vision rehabilitation providers in France, and identified barriers to the creation, development, dissemination, and implementation of Virtual Reality (VR) technology in low vision rehabilitation clinical practice. In this article, the term VR specifically refers to head-mounted displays that project interactive 3D worlds, providing highly immersive solutions that can be exploited in low vision rehabilitation.

Although historically VR has mainly been used in the gaming industry, its application has recently expanded into healthcare for the medical education and for the treatment of a variety of conditions such as anxiety disorders, reducing fall risks in older adults, paincontrol, obesity-management, distraction during wound care, and as an adjunctive physical therapy tool [32-59]. However, despite an increasing awareness about the potential benefits of VR, this technology has not been fully developed for use in rehabilitation and it is only starting to be applied in the field of low vision rehabilitation. Understanding providers' needs, concerns about effectiveness, ease-of-use, and accessibility of VR technology is critical to ensuring the success of VR interventions and rehabilitation.

\section{Materials and Methods}

\section{Study population and data collection}

All graduates of French orthoptist training programs (whether in practice or not) and all currently enrolled students were eligible to participate. An online questionnaire (Google Form) was used to collect data. This form was chosen for its ease of administration, data collection, and greater likelihood of soliciting participation, because respondents could complete the survey at their convenience. All respondents received the same questionnaire link. However, the questions varied depending on the respondent's indication of whether he/she was a (a) graduate versus student, (b) low vision rehabilitation provider versus non-provider, or (c) low vision rehabilitation provider treating versus not treating AMD patients. A multiple-choice question format with an additional free-text option was used to survey practice methodology (including frequency and content of rehabilitation training), provider's gender and educational background (year of graduation and university attended), sector, and geographic location of practice.

In order to solicit as many potential respondents as possible, a study participation invitation along with a link to the questionnaire was emailed twice to potential subjects of each orthoptic graduate school, all the various orthoptist labor unions, several large French teaching hospitals that have ophthalmology units, and posted three times (October 2017, December 2017, and January 2018) on a Facebook page called "2 Eyes", which lists nearly $98 \%$ of all French orthoptists. In exhausting these channels, our advertisements theoretically reached nearly all 4,643 French orthoptists nationwide-both students still in training and orthoptists in practice. Online responses were accepted from October 2017 to February 2018 and they were recorded in a database for analysis.

\section{Data analysis}

The analysis of gathered data was stratified across three distinct demographics: graduates versus students; low vision rehabilitation providers versus non-providers; and among low vision rehabilitation providers, those whose practice comprises more than $10 \%$ versus less than $10 \%$ AMD patients.

All statistical analyses were performed on STATA (v. 14.2) and graphical representations were built on MS Excel (2016). Standard descriptive methods were used for demographic analysis with medians of 95\% binomial-exact (conservative) confidence intervals and an alpha level of 0.05 considered statistically significant. Differences in demographic, training, and opinion regarding VR variables were compared in students versus graduates; and among graduates, low vision rehabilitation providers versus non-providers. Percentage and Pearson's Chi-squared tests were used to assess the statistical significance among nominal variables. Continuous variables were analyzed using Student's t-test. Those variables found to be statistically significant were then included in multiple logistic regression models to determine independent relationships.

\section{Ethics}

This study was conducted by the Silver Sight Chair at the Vision Institute (Paris, France) in accordance with the tenets of the Declaration of Helsinki and ethically approved by "CPP Ile de France V" (ID_RCB 2015-A01094-45, n. CPP: 16122 MSB). All participants gave informed consent approval for the de-identified publication of their data.

\section{Results}

\section{Validity of the study population}

Out of the 529 responses received, 471 met inclusion criteria (44 were rejected due to an invalid email and 14 replied more than once). The sample comprised 110 students and 361 graduates. Graduate orthoptists accounted for $7.78 \%$ of the 4643 French orthoptists nationwide, with a margin of error of $4.95 \%$ (CI=95\%). As it is not possible to quantify how many orthoptists saw our advertisements soliciting study participation, we cannot calculate the response rate.

Gender and geographic demographics of respondents were representatives of the overall orthoptist population based on the 2017 consensus of French orthoptists [60]. However, the regions of Ile de France (comprising $29.28 \%$ of orthoptists in the sample vs. $22.57 \%$ of the general orthoptist population; $\mathrm{p}=0.0035$ ) and Auvergne Rhone Alpes (accounting for $18.50 \%$ of orthoptists in the sample $v s .12 .66 \%$ of the general orthoptist population; $\mathrm{p}=0.0015)$ were slightly overrepresented, whereas the regions of Occitanie (comprising $8.56 \%$ of orthoptists in the sample vs. $13.22 \%$ of the general orthoptist population; $\mathrm{p}=0.0108)$ and Provence Alpes Cote d'Azur (6.07\% of orthoptists in the sample vs. $9.69 \%$ of the general orthoptist population; $\mathrm{p}=0.0235$ ) were slightly under-represented (Figure 1). Given that the title of our study included the term "low vision rehabilitation", a possible self-selection bias exists favoring a higher proportion of low vision rehabilitation provider respondents.

\section{Demographic characteristics of the sample}

The demographic characteristics of the sampled study population are reported in Table 1. The average date of orthoptist graduation was $2008 \pm(S D) 3.27$ years $(n=361)$. Among the sampled graduates, $69.66 \%$ practice in an urban setting. Almost half of these $(47.75 \%, n=171)$ reported having provided low vision rehabilitation at least once in the past year. Only $17.06 \%(n=29)$ of these providers (accounting for $8.03 \%$ of the total orthoptist sample) stated that low vision rehabilitation is the main therapeutic modality used in their practice.

Similarly, only $39.61 \%$ of graduates reported having received a minimal level of training in low vision rehabilitation and $18.84 \%$ reported no exposure to low vision rehabilitation during their orthoptic curriculum. Even if they had wanted to train in low vision rehabilitation as a student, $37.12 \%$ of graduates stated that it was not offered during their internship year. Of the 227 graduates who were exposed to low vision rehabilitation during their internship, only $6.09 \%$ had the opportunity to regularly practice it during their training. Interestingly, we did not find any correlation between a practitioner's extent of training in low vision rehabilitation and his willingness to provide it (chi 
Citation: Raphanel M, Shaughness G, Seiple WH, Arleo A (2018) Current Practice in Low Vision Rehabilitation of Age-related Macular Degeneration and Usefulness of Virtual Reality as a Rehabilitation Tool. Aging Sci 6: 194. doi: 10.4172/2329-8847.1000194

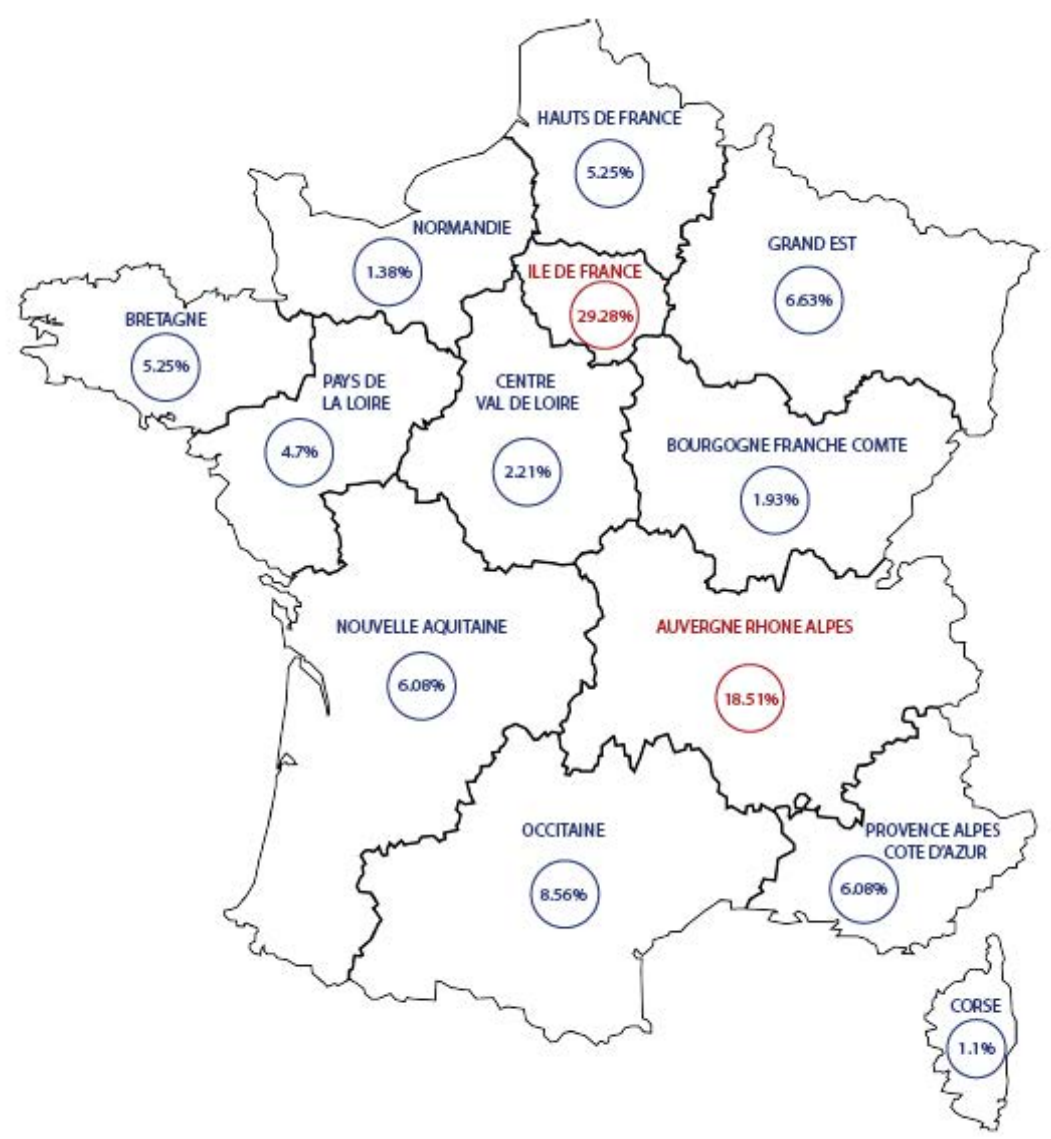

Geographic distribution of the French study population

Figure 1: Geographic distribution of sampled graduate orthoptist respondents. A total of $n=471$ orthoptists (110 students and 361 graduates) were sampled across France. The two most represented regions, lle de France (greater metropolitan Paris) and Auvergne Rhone Alpes (greater metropolitan Lyon), are shown in red.

\begin{tabular}{|c|c|c|c|c|c|c|c|c|c|c|}
\hline \multirow{2}{*}{ Demographic Characteristic } & \multicolumn{2}{|c|}{ Total } & \multicolumn{2}{|c|}{ Students } & \multicolumn{2}{|c|}{ Graduates } & \multicolumn{2}{|c|}{ LVR } & \multicolumn{2}{|c|}{ Non-LVR } \\
\hline & $\mathbf{n}$ & $\%$ & $\mathbf{n}$ & $\%$ & $\mathbf{n}$ & $\%$ & $\mathbf{n}$ & $\%$ & $\mathbf{n}$ & $\%$ \\
\hline Sex & 471 & & 110 & & 361 & & 17 & $47.75 \%$ & 18 & $52.25 \%$ \\
\hline Female & 431 & $91.51 \%$ & 100 & $90.91 \%$ & 331 & $91.69 \%$ & 16 & $97.06 \%$ & 16 & $86.56 \%$ \\
\hline Male & 40 & $8.49 \%$ & 10 & $9.09 \%$ & 30 & $8.31 \%$ & 5 & $2.94 \%$ & 25 & $13.44 \%$ \\
\hline University & 471 & & 110 & & 361 & & 17 & & 18 & \\
\hline Paris 6 & 137 & $29.09 \%$ & 31 & $28.18 \%$ & 106 & $29.36 \%$ & 38 & $22.35 \%$ & 66 & $35.48 \%$ \\
\hline Lyon & 55 & $11.68 \%$ & 7 & $6.36 \%$ & 48 & $13.30 \%$ & 20 & $11.76 \%$ & 26 & $13.98 \%$ \\
\hline Paris 5 & 39 & $8.28 \%$ & 11 & $10.00 \%$ & 28 & $7.76 \%$ & 11 & $6.47 \%$ & 17 & $9.14 \%$ \\
\hline Montpellier & 27 & $5.73 \%$ & 2 & $1.82 \%$ & 25 & $6.93 \%$ & 19 & $11.18 \%$ & 6 & $3.23 \%$ \\
\hline Nantes & 16 & $3.40 \%$ & 9 & $8.18 \%$ & 7 & $1.94 \%$ & 2 & $1.18 \%$ & 5 & $2.69 \%$ \\
\hline Strasbourg & 23 & $4.88 \%$ & 8 & $7.27 \%$ & 15 & $4.16 \%$ & 6 & $3.53 \%$ & 9 & $4.84 \%$ \\
\hline Rennes & 31 & $6.58 \%$ & 9 & $8.18 \%$ & 22 & $6.09 \%$ & 13 & $7.65 \%$ & 9 & $4.84 \%$ \\
\hline Amiens & 12 & $2.55 \%$ & 8 & $7.27 \%$ & 4 & $1.11 \%$ & 1 & $0.59 \%$ & 3 & $1.61 \%$ \\
\hline Lille & 16 & $3.40 \%$ & 3 & $2.73 \%$ & 13 & $3.60 \%$ & 7 & $4.12 \%$ & 6 & $3.23 \%$ \\
\hline Bordeaux & 25 & $5.31 \%$ & 6 & $5.45 \%$ & 19 & $5.26 \%$ & 13 & $7.65 \%$ & 6 & $3.23 \%$ \\
\hline Toulouse & 25 & $5.31 \%$ & 1 & $0.91 \%$ & 24 & $6.65 \%$ & 17 & $10.00 \%$ & 7 & $3.76 \%$ \\
\hline Tours & 16 & $3.40 \%$ & 8 & $7.27 \%$ & 8 & $2.22 \%$ & 2 & $1.18 \%$ & 5 & $2.69 \%$ \\
\hline Marseille & 16 & $3.40 \%$ & 3 & $2.73 \%$ & 13 & $3.60 \%$ & 7 & $4.12 \%$ & 6 & $3.23 \%$ \\
\hline Clermont Ferrand & 22 & $4.67 \%$ & 4 & $3.64 \%$ & 18 & $4.99 \%$ & 9 & $5.29 \%$ & 9 & $4.84 \%$ \\
\hline Nancy & 11 & $2.34 \%$ & & $0.00 \%$ & 11 & $3.05 \%$ & 5 & $2.94 \%$ & 6 & $3.23 \%$ \\
\hline Pursued Continuing Education After Graduation? & 471 & & 110 & & 361 & & 17 & & 18 & \\
\hline Yes & 137 & $29.09 \%$ & 43 & $39.09 \%$ & 94 & $26.04 \%$ & 55 & $32.35 \%$ & 37 & $19.89 \%$ \\
\hline
\end{tabular}


Citation: Raphanel M, Shaughness G, Seiple WH, Arleo A (2018) Current Practice in Low Vision Rehabilitation of Age-related Macular Degeneration and Usefulness of Virtual Reality as a Rehabilitation Tool. Aging Sci 6: 194. doi: 10.4172/2329-8847.1000194

Page 4 of 13

\begin{tabular}{|c|c|c|c|c|c|c|c|c|c|c|}
\hline No & 327 & $69.43 \%$ & 60 & $54.55 \%$ & 267 & $73.96 \%$ & 11 & $67.65 \%$ & 14 & $80.11 \%$ \\
\hline Don't know & 7 & $1.49 \%$ & 7 & $6.36 \%$ & & & & & & \\
\hline Sector of Practice & 466 & & 110 & & 356 & & 17 & & 18 & \\
\hline Rural & 68 & $14.59 \%$ & 27 & $24.55 \%$ & 41 & $11.52 \%$ & 23 & $13.53 \%$ & 18 & $9.68 \%$ \\
\hline Urban & 322 & $69.10 \%$ & 74 & $67.27 \%$ & 248 & $69.66 \%$ & 10 & $63.53 \%$ & 14 & $75.27 \%$ \\
\hline Mixed & 76 & $16.31 \%$ & 9 & $8.18 \%$ & 67 & $18.82 \%$ & 39 & $22.94 \%$ & 28 & $15.05 \%$ \\
\hline \multicolumn{11}{|l|}{ Training Background } \\
\hline Did you practice LVR while a student? & 471 & & 110 & & 361 & & 17 & & 18 & \\
\hline Never & 174 & $36.94 \%$ & 40 & $36.36 \%$ & 134 & $37.12 \%$ & 59 & $34.71 \%$ & 74 & $39.78 \%$ \\
\hline Basic Introduction & 196 & $41.61 \%$ & 46 & $41.82 \%$ & 150 & $41.55 \%$ & 66 & $38.82 \%$ & 80 & $43.01 \%$ \\
\hline Occasionally & 74 & $15.71 \%$ & 19 & $17.27 \%$ & 55 & $15.24 \%$ & 31 & $18.24 \%$ & 24 & $12.90 \%$ \\
\hline Regularly & 27 & $5.73 \%$ & 5 & $4.55 \%$ & 22 & $6.09 \%$ & 14 & $8.24 \%$ & 8 & $4.30 \%$ \\
\hline Did your training increase your desire to provide LVR? & 297 & & 70 & & 227 & & 11 & & 11 & \\
\hline 1 & 36 & $12.12 \%$ & 8 & $11.43 \%$ & 28 & $12.33 \%$ & 7 & $6.31 \%$ & 21 & $18.75 \%$ \\
\hline 2 & 57 & $19.19 \%$ & 8 & $11.43 \%$ & 49 & $21.59 \%$ & 15 & $13.51 \%$ & 33 & $29.46 \%$ \\
\hline 3 & 54 & $18.18 \%$ & 8 & $11.43 \%$ & 46 & $20.26 \%$ & 16 & $14.41 \%$ & 28 & $25.00 \%$ \\
\hline 4 & 64 & $21.55 \%$ & 20 & $28.57 \%$ & 44 & $19.38 \%$ & 27 & $24.32 \%$ & 16 & $14.29 \%$ \\
\hline 5 & 59 & $19.87 \%$ & 20 & $28.57 \%$ & 39 & $17.18 \%$ & 30 & $27.03 \%$ & 9 & $8.04 \%$ \\
\hline 6 & 27 & $9.09 \%$ & 6 & $8.57 \%$ & 21 & $9.25 \%$ & 16 & $14.41 \%$ & 5 & $4.46 \%$ \\
\hline Did you study LVR? & 471 & & 110 & & 361 & & 17 & & 18 & \\
\hline Never & 80 & $16.99 \%$ & 12 & $10.91 \%$ & 68 & $18.84 \%$ & 42 & $24.71 \%$ & 26 & $13.98 \%$ \\
\hline Basic Introduction & 115 & $24.42 \%$ & 11 & $10.00 \%$ & 104 & $28.81 \%$ & 52 & $30.59 \%$ & 50 & $26.88 \%$ \\
\hline Occasionally & 192 & $40.76 \%$ & 49 & $44.55 \%$ & 143 & $39.61 \%$ & 60 & $35.29 \%$ & 82 & $44.09 \%$ \\
\hline Regularly & 84 & $17.83 \%$ & 38 & $34.55 \%$ & 46 & $12.74 \%$ & 16 & $9.41 \%$ & 28 & $15.05 \%$ \\
\hline Did your courses increase your desire to provide LVR? & 391 & & 98 & & 293 & & 12 & & 16 & \\
\hline 1 & 43 & $11.00 \%$ & 6 & $6.12 \%$ & 37 & $12.63 \%$ & 8 & $6.25 \%$ & 29 & $18.13 \%$ \\
\hline 2 & 74 & $18.93 \%$ & 17 & $17.35 \%$ & 57 & $19.45 \%$ & 20 & $15.63 \%$ & 37 & $23.13 \%$ \\
\hline 3 & 104 & $26.60 \%$ & 19 & $19.39 \%$ & 85 & $29.01 \%$ & 44 & $34.38 \%$ & 37 & $23.13 \%$ \\
\hline 4 & 79 & $20.20 \%$ & 21 & $21.43 \%$ & 58 & $19.80 \%$ & 23 & $17.97 \%$ & 34 & $21.25 \%$ \\
\hline 5 & 62 & $15.86 \%$ & 22 & $22.45 \%$ & 40 & $13.65 \%$ & 20 & $15.63 \%$ & 20 & $12.50 \%$ \\
\hline 6 & 29 & $7.42 \%$ & 13 & $13.27 \%$ & 16 & $5.46 \%$ & 13 & $10.16 \%$ & 3 & $1.88 \%$ \\
\hline Did you feel confident in your ability to practice LVR & 471 & & 110 & & 361 & & 17 & & 18 & \\
\hline 1 & 221 & $46.92 \%$ & 24 & $21.82 \%$ & 197 & $54.57 \%$ & 80 & $47.06 \%$ & 11 & $61.29 \%$ \\
\hline 2 & 97 & $20.59 \%$ & 29 & $26.36 \%$ & 68 & $18.84 \%$ & 27 & $15.88 \%$ & 39 & $20.97 \%$ \\
\hline 3 & 70 & $14.86 \%$ & 22 & $20.00 \%$ & 48 & $13.30 \%$ & 30 & $17.65 \%$ & 18 & $9.68 \%$ \\
\hline 4 & 52 & $11.04 \%$ & 24 & $21.82 \%$ & 28 & $7.76 \%$ & 20 & $11.76 \%$ & 8 & $4.30 \%$ \\
\hline 5 & 20 & $4.25 \%$ & 7 & $6.36 \%$ & 13 & $3.60 \%$ & 8 & $4.71 \%$ & 5 & $2.69 \%$ \\
\hline 6 & 11 & $2.34 \%$ & 4 & $3.64 \%$ & 7 & $1.94 \%$ & 5 & $2.94 \%$ & 2 & $1.08 \%$ \\
\hline
\end{tabular}

Table 1: Demographic and training characteristics of respondents. The sampled orthoptists were asked to characterize their training in low vision rehabilitation (LVR) and their confidence to practice LVR after graduation (range 1 to 6 : score 1 = 'not confident at all', 6 ='fully confident').

squared theoretical $5 \%=7.82$ Pearson chi squared calculated $=4.852168$; $\mathrm{df}=3, \mathrm{p}=0.18296) .26 .4 \%$ of graduates endorsed pursuing continuing education and $39.09 \%$ of students stated they intend to pursue further training upon graduation.

A statistically significant correlation between the year of graduation, or anticipated graduation, and whether the respondent had received training in low vision rehabilitation was observed $(\mathrm{n}=471, \mathrm{r}=0.425347$; $\mathrm{p}<0.0000001)$. There was no significant correlation between the year of graduation, or anticipated graduation, and the opportunity for a respondent to obtain low vision training during his/her internship if desired $(\mathrm{N}=471, \mathrm{r}=0.082606 ; \mathrm{p}=0.073285)$. Only $1.93 \%$ of graduates reported that they were confident in their ability to provide low vision rehabilitation upon graduation, whereas $86.71 \%$ were either neutral or not at all confident (Figure 2).

\section{Differences between low vision rehabilitation providers and} non-providers

An orthoptist's likelihood of providing low vision rehabilitation was correlated to the university where he/she trained (chi squared theoretical $5 \%=23.69<$ Pearson chi squared calculated $=27.5925 ; \mathrm{df}=14$, $\mathrm{p}=0.016117$ ) (Figure 3 ). The quality of an orthoptist's training may thus contribute to his/her confidence in being able to perform low vision rehabilitation (Figure 4). Women are 5.13 times more likely to practice low vision training than men (odds ratio=5.13, IC $=[1.9153 ; 13.7187]$; Pearson chi squared $=17.57787 ; \mathrm{df}=6 ; \mathrm{p}=0.00738$ ). Half of all female providers offered low vision rehabilitation upon graduation compared to only $20 \%$ of male providers (chi squared theoretical $5 \%=3.84<$ Pearson chi squared calculated $=12.68894 ; \mathrm{df}=1, \mathrm{p}=0.00037$ ). Reasons cited by respondents for not providing low vision rehabilitation are described in Table 2. Almost half of non-providers (49.46\%) attribute their reticence to lack of confidence in their low vision rehabilitation training. Approximately two thirds (66.67\%) report that it is not in their scope of practice, whether because they are employed by an ophthalmologist under whom they cannot provide these services, or because they work in a hospital that does not have a low vision rehabilitation department.

As shown in Table 3, 61.18\% ( $\mathrm{n}=170)$ of low vision providers report that rehabilitation represents less than $10 \%$ of their work. $45.25 \%$ of 


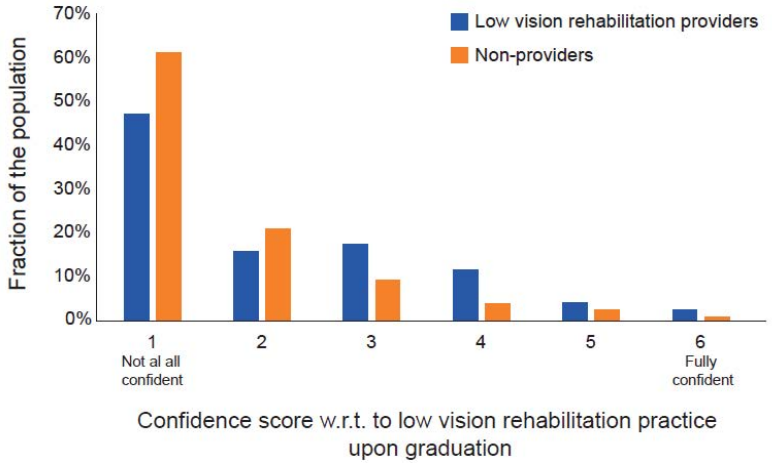

Figure 2: Confidence score with respect to low vision rehabilitation practice upon graduation. Both low vision rehabilitation providers and non-providers responded to the question: "Upon graduation, did you feel confident in your ability to practice low vision rehabilitation?" with a scale of 1 to 6 (1=not all confident; $6=$ fully confident). The score distribution is significantly biased towards 1 , with $47.06 \%$ of current low vision rehabilitation providers and $61.29 \%$ of non-providers that were not at all confident in their ability to practice low vision rehabilitation upon graduation.

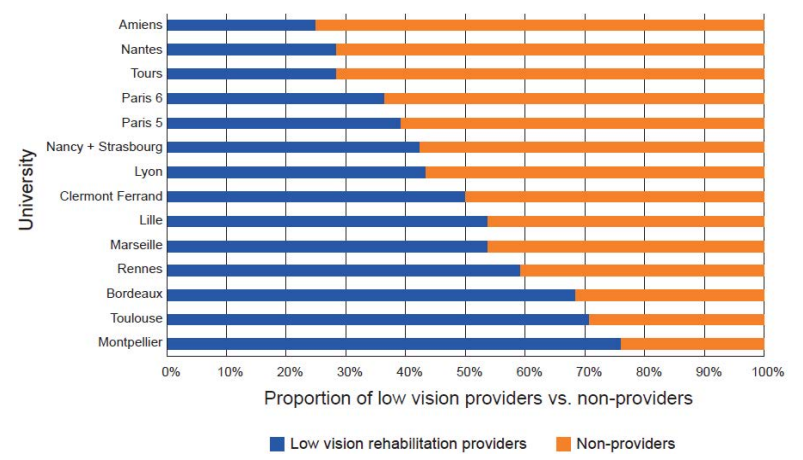

Figure 3: Likelihood of providing low vision rehabilitation as a function of the university where the orthoptist respondent graduated. The diagram shows a clear relation between the University of Origin and the probability of becoming a low vision rehabilitation provider upon graduation. Interestingly, this relation is not determined by the number of orthoptist that graduate from a given university. For instance, only $36.54 \%$ of graduated from the University of Paris 6 (which trained about one third of all French orthoptists) were likely to provide low vision rehabilitation, whereas a majority of orthoptists that graduated from the University of Montpellier and from the University of Toulouse $(76 \%$ and $70.83 \%$, respectively), did practice low vision rehabilitation (despite the small number of the orthoptists trained by these universities).

these providers complete additional training before rehabilitating their first low vision patient and $53.25 \%$ of practitioners state this is due to insufficient training in their orthoptic curriculum. $17.20 \%$ of orthoptists who do not pursue additional training cite lack of funds and $36.56 \%$ report they prefer instead to refer to colleagues. Only $11.83 \%$ of orthoptists report sufficiently confident in their prior training to not require additional training. A majority (63\%) of providers do not regularly read international scientific papers on low vision rehabilitation, although they are slightly more apt to read French peer-reviewed articles (Figure 5). In addition to orthoptists, opticians $(77.93 \%)$ are the primary other practitioners specializing in low vision rehabilitation. However, only one third of orthoptist low vision providers coordinate care with a psychomotor, occupational, or mobility therapist. Only $29.76 \%$ of providers report a positive working relationship with the prescribing ophthalmologist and $20.83 \%$ report no interaction at all.

\section{Low vision rehabilitation of AMD patients}

As described in Table 4, 123 of 171 graduate low vision rehabilitation providers reported an AMD patient population representing more than $10 \%$ of their practice. In general, more than half of these practitioners saw an AMD patient once per week (55.28\%) for an average of $15 \pm 8$ sessions $(\min =5 ; \max =50)$. The initial intake averaged $77 \pm 29$ minutes $(\mathrm{n}=123 ; \min =30 ; \max =180)$, most often divided over two sessions. Follow-up visits averaged $54 \pm 9$ minutes $(n=123, \min =25$; $\max =60)$. Almost half (53.66\%) of all patients were classified as meeting WHO stage 1 criteria for visual impairment, whereas $13.82 \%$ of patients met pre-stage 1 criteria (no visual impairment) and $22.76 \%$ met stage 2 criteria. Almost half (44.72\%) of providers reported not offering rehabilitation once patients reach stage 3 criteria due to consensus that at this point, visual loss is too far progressed to benefit from therapy. Factors influencing which therapeutic modality these providers employed in the treatment of AMD patients included their colleagues' recommendations $(51.22 \%)$, past training in a given modality $(48.78 \%)$, and personal professional experience $(45.53 \%)$.

We observed a large variability in the functional capacities rehabilitated through low vision training (Figure 6). $93 \%$ of practitioner's trained hand-eye coordination, $65 \%$ sought to identify a patient's preferred retinal locus (PRL), and $32.26 \%$ tested postural stability. Marked disparities between rehabilitation methodologies are also evident. For example, to identify a patient's PRL, practitioners varied between using subjective measures ( $71.25 \%$ of providers use a Goldman field test and $43.75 \%$ use pupillary reflection) and objectives measures (11.25\% use microperimetry MP1, and 10\% employ retinography).

\section{Usefulness of virtual reality for low vision rehabilitation of AMD patients}

Finally, we inquired about practitioners' willingness to try new methodologies for low vision rehabilitation (Figure 7). In general, orthoptists (both graduates and students) were receptive to new technologies $($ mean $=4.568 \pm 0.981 ; \mathrm{n}=470)$ such as $\mathrm{VR}($ mean $=4.417$ $\pm 1.1847 ; \mathrm{n}=470)$. On a scale of 1 to $6(1=$ completely disagree,

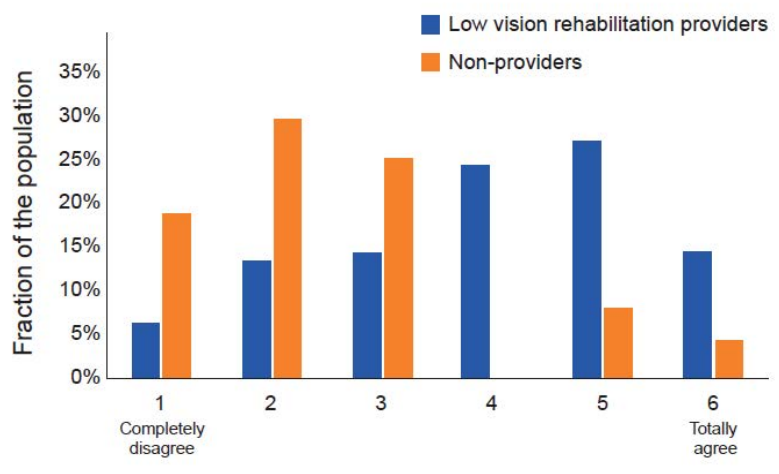

Willingness score w.r.t. low vision rehabilitation upon internship training

Figure 4: Willingness score with respect to low vision rehabilitation practice upon internship training in low vision rehabilitation. Both low vision rehabilitation providers and non-providers responded to the question: "Did your internship in low vision rehabilitation increase your desire to practice it?" with a scale of 1 to 6 ( $1=$ completely disagree; $6=$ totally agree $)$. For the majority of providers, their training internship in low vision rehabilitation increased their desire to practice it (mode score=5, with $27.03 \%$ of the respondents; median score $=4$, with $58.56 \%$ of the respondents). The opposite holds for non-providers (mode score $=2$, with $29.46 \%$ of respondents; median score $=3$, with $73,21 \%$ of respondent with a score of 3 or less). 
Citation: Raphanel M, Shaughness G, Seiple WH, Arleo A (2018) Current Practice in Low Vision Rehabilitation of Age-related Macular Degeneration and Usefulness of Virtual Reality as a Rehabilitation Tool. Aging Sci 6: 194. doi: 10.4172/2329-8847.1000194

\begin{tabular}{|c|c|c|}
\hline Non-LVR providers $(n=186)$ & $\mathbf{n}$ & Percent \\
\hline Not enough demand. & 32 & $17.20 \%$ \\
\hline Not requested by my patients or prescribers and I wish it were. & 10 & $5.38 \%$ \\
\hline Not requested by my patients or prescribers and I am satisfied with it not being requested. & 22 & $11.83 \%$ \\
\hline I am not confident enough in my ability to perform this modality. & 92 & $49.46 \%$ \\
\hline My work does not permit it. & 124 & $66.67 \%$ \\
\hline And I wish it were. & 49 & $26.34 \%$ \\
\hline No occasion to practice it and I wish it were. & 13 & $6.99 \%$ \\
\hline And I am satisfied with it not being requested. & 62 & $33.33 \%$ \\
\hline I don't like LVR. & 42 & $22.58 \%$ \\
\hline No interest in LVR. & 2 & $1.08 \%$ \\
\hline I don't believe LVR is effective. & 3 & $1.61 \%$ \\
\hline Takes too long. & 15 & $8.06 \%$ \\
\hline Too much emotional investment. & 22 & $11.83 \%$ \\
\hline Financial reasons. & 24 & $12.90 \%$ \\
\hline This activity does not pay enough. & 6 & $3.23 \%$ \\
\hline Equipment too expensive. & 18 & $9.68 \%$ \\
\hline
\end{tabular}

Table 2: Reasons cited by respondents for not providing low vision rehabilitation to their visually impaired patients. We classified all answers in different categories, such as financial reasons, confidence in their practice, patient demand, respondent's wish to practice or not low vision rehabilitation, respondent's satisfaction with respect to low vision rehabilitation).

\begin{tabular}{|c|c|c|}
\hline Questions & $\mathbf{n}$ & $\%$ \\
\hline \multicolumn{3}{|l|}{ What percentage of your work includes LVR? N=170 } \\
\hline $0 \%$ to $10 \%$ & 104 & $61.18 \%$ \\
\hline $10 \%$ to $30 \%$ & 30 & $17.65 \%$ \\
\hline $30 \%$ to $50 \%$ & 7 & $4.12 \%$ \\
\hline $50 \%$ to $70 \%$ & 10 & $5.88 \%$ \\
\hline $70 \%$ to $90 \%$ & 4 & $2.35 \%$ \\
\hline $90 \%$ to $100 \%$ & 15 & $8.82 \%$ \\
\hline \multicolumn{3}{|c|}{ Did you complete additional continuing education in LVR before offering this to a patient? $N=170$} \\
\hline No & 93 & $54.71 \%$ \\
\hline Yes & 77 & $45.29 \%$ \\
\hline \multicolumn{3}{|l|}{ If you answered yes, why? $\mathrm{N}=77$} \\
\hline I did not feel comfortable enough with my level of training in orthoptic school. & 41 & $53.25 \%$ \\
\hline I feel continuing education is necessary to maintain a level of professional competency. & 27 & $35.06 \%$ \\
\hline I had already been in practice for a long time before receiving my first low vision patient and I needed a refresher. & 5 & $6.49 \%$ \\
\hline I wanted to have the most up-to-date training. & 4 & $5.19 \%$ \\
\hline \multicolumn{3}{|l|}{ Did your training in LVR before graduation meet your expectations? $N=77$} \\
\hline Yes & 65 & $84.42 \%$ \\
\hline No (not enough opportunities to practice) & 12 & $15.58 \%$ \\
\hline \multicolumn{3}{|l|}{ If you did not pursue additional training in LVR, why? $\mathrm{N}=93$} \\
\hline I can ask advices to my colleagues to provide LVR. & 34 & $36.56 \%$ \\
\hline I can't afford the training fees. & 16 & $17.20 \%$ \\
\hline I don't have enough time. & 12 & $12.90 \%$ \\
\hline Not enough patient demand to justify the cost of training. & 12 & $12.90 \%$ \\
\hline My theoretical training has already sufficiently prepared me clinically. & 11 & $11.83 \%$ \\
\hline I already feel competent. & 5 & $5.38 \%$ \\
\hline I don't know of any programs that meet my expectations. & 3 & $3.23 \%$ \\
\hline \multicolumn{3}{|c|}{ Do you regularly read international scientific articles on LVR? N=170 (1=never; 6=very regularly) } \\
\hline 1 & 28 & $16 \%$ \\
\hline 2 & 33 & $19 \%$ \\
\hline 3 & 48 & $28 \%$ \\
\hline 4 & 31 & $18 \%$ \\
\hline 5 & 19 & $11 \%$ \\
\hline 6 & 11 & $6 \%$ \\
\hline \multicolumn{3}{|c|}{ Do you regularly read French professional journals on LVR? (For example, Le journal français d'orthoptie) $N=170$ (1=never; $6=$ very regularly) } \\
\hline 1 & 2 & $1.18 \%$ \\
\hline 2 & 13 & $7.65 \%$ \\
\hline 3 & 38 & $22.35 \%$ \\
\hline 4 & 40 & $23.53 \%$ \\
\hline 5 & 42 & $24.71 \%$ \\
\hline 6 & 35 & $20.59 \%$ \\
\hline
\end{tabular}


Citation: Raphanel M, Shaughness G, Seiple WH, Arleo A (2018) Current Practice in Low Vision Rehabilitation of Age-related Macular Degeneration and Usefulness of Virtual Reality as a Rehabilitation Tool. Aging Sci 6: 194. doi: 10.4172/2329-8847.1000194

Page 7 of 13

\begin{tabular}{|c|c|c|}
\hline \multicolumn{3}{|c|}{ Interaction with other healthcare providers } \\
\hline \multicolumn{3}{|c|}{ Interaction with ophthalmologist $\mathrm{n}=170$} \\
\hline They don't believe in the effectiveness of LVR & 8 & $4.76 \%$ \\
\hline Non-existent & 35 & $20.83 \%$ \\
\hline Difficult initially, but now they accept LVR & 4 & $2.38 \%$ \\
\hline Cordial & 70 & $41.67 \%$ \\
\hline Excellent & 50 & $29.76 \%$ \\
\hline \multicolumn{3}{|c|}{ Do you work with other LVR providers? $\mathrm{N}=170$} \\
\hline Yes & 145 & $85.29 \%$ \\
\hline No & 25 & $14.71 \%$ \\
\hline \multicolumn{3}{|c|}{ With which LVR providers do you work? $\mathrm{N}=145$ (multiple answers possible) } \\
\hline Optician specialized in low vision & 113 & $77.93 \%$ \\
\hline LVR orthoptists & 85 & $58.62 \%$ \\
\hline Psychomotor therapist & 48 & $33.10 \%$ \\
\hline Occupational therapist & 44 & $30.34 \%$ \\
\hline Mobility instructors & 43 & $29.66 \%$ \\
\hline A specialized institute & 7 & $4.83 \%$ \\
\hline Therapist specialized in ADLs & 6 & $4.14 \%$ \\
\hline Therapist & 2 & $1.38 \%$ \\
\hline Teacher & 2 & $1.38 \%$ \\
\hline Transcriptor & 2 & $1.38 \%$ \\
\hline
\end{tabular}

Table 3: TFocus on the characteristics of low vision rehabilitation providers. The sub-sample of providers were asked to quantify how often they practice low vision rehabilitation, their in-service training, their interaction with other healthcare providers, and how often they read scientific literature about low vision rehabilitation.

\begin{tabular}{|c|c|c|}
\hline \multirow{2}{*}{ Methodology } & \multicolumn{2}{|c|}{ LVR } \\
\hline & $\mathbf{n}$ & $\%$ \\
\hline \multicolumn{3}{|c|}{ How often do you see your AMD patients? $\mathrm{N}=123$} \\
\hline Once per trimester & 1 & 0.0081 \\
\hline Once per month & 15 & 0.122 \\
\hline 2 times per week & 33 & 0.2683 \\
\hline Once per week initially, then twice per month & 4 & 0.0325 \\
\hline Once per week & 68 & 0.5528 \\
\hline More than once per week & 2 & 0.0163 \\
\hline \multicolumn{3}{|c|}{ At what WHO clinical stage of low vision do you start LVR? N=123 } \\
\hline Before Stage 1 & 17 & $13.82 \%$ \\
\hline Stage 1 & 66 & $53.66 \%$ \\
\hline Stage 2 & 28 & $22.76 \%$ \\
\hline Stage 3 & 10 & $8.13 \%$ \\
\hline Stage 4 & 1 & $0.81 \%$ \\
\hline Stage 5 & 1 & $0.81 \%$ \\
\hline \multicolumn{3}{|c|}{ At what WHO clinical stage of low vision do you stop LVR? $n=123$} \\
\hline Stage 1 & 7 & $5.69 \%$ \\
\hline Stage 2 & 10 & $8.13 \%$ \\
\hline Stage 3 & 22 & $17.89 \%$ \\
\hline Stage 4 & 55 & $44.72 \%$ \\
\hline Stage 5 & 29 & $23.58 \%$ \\
\hline \multicolumn{3}{|c|}{ How do you choose your methodology? $N=123$} \\
\hline Recommendation of my colleagues & 63 & $51.22 \%$ \\
\hline My past training & 60 & $48.78 \%$ \\
\hline My own methodology based on my experience & 56 & $45.53 \%$ \\
\hline Textbook & 42 & $34.15 \%$ \\
\hline Internship & 42 & $34.15 \%$ \\
\hline Articles & 26 & $21.14 \%$ \\
\hline Internet & 13 & $10.57 \%$ \\
\hline \multicolumn{3}{|c|}{ Do you identify the patient's PRL? } \\
\hline Yes & 80 & $65.04 \%$ \\
\hline No & 43 & $34.96 \%$ \\
\hline \multicolumn{3}{|l|}{ How do you identify the patient's PRL? } \\
\hline Goldman visual field test & 57 & $71.25 \%$ \\
\hline Observation of pupillary reflections & 35 & $43.75 \%$ \\
\hline MP1 & 9 & $11.25 \%$ \\
\hline
\end{tabular}


Citation: Raphanel M, Shaughness G, Seiple WH, Arleo A (2018) Current Practice in Low Vision Rehabilitation of Age-related Macular Degeneration and Usefulness of Virtual Reality as a Rehabilitation Tool. Aging Sci 6: 194. doi: 10.4172/2329-8847.1000194

Page 8 of 13

\begin{tabular}{|c|c|c|}
\hline Retinophotography & 8 & $10.00 \%$ \\
\hline Clock test & 2 & $2.50 \%$ \\
\hline Amsler & 1 & $1.25 \%$ \\
\hline \multicolumn{3}{|c|}{ Do you train hand-eye coordination? $\mathrm{N}=123$} \\
\hline Yes & 11 & $92.68 \%$ \\
\hline No & 9 & $7.32 \%$ \\
\hline \multicolumn{3}{|c|}{ How do you train hand-eye coordination? $\mathrm{N}=114$} \\
\hline Étoile de thomas & 92 & $81 \%$ \\
\hline Test de barrage & 90 & $78.95 \%$ \\
\hline Fixation balls & 75 & $65.79 \%$ \\
\hline E de weiss & 51 & $44.74 \%$ \\
\hline Home-made creation or turning game & 20 & $17.54 \%$ \\
\hline Computer tablet & 2 & $1.75 \%$ \\
\hline \multicolumn{3}{|c|}{ Do you test facial recognition? $\mathrm{N}=123$} \\
\hline Yes & 63 & $50.81 \%$ \\
\hline No & 60 & $48.39 \%$ \\
\hline \multicolumn{3}{|c|}{ Do you test postural stability? $\mathrm{N}=123$} \\
\hline Yes & 40 & $32.26 \%$ \\
\hline No & 83 & $66.94 \%$ \\
\hline \multicolumn{3}{|c|}{ Do you test reading speed? $\mathrm{N}=123$} \\
\hline Yes & 10 & $86.18 \%$ \\
\hline No & 17 & $13.82 \%$ \\
\hline \multicolumn{3}{|c|}{ How do you test reading speed? $\mathrm{N}=106$} \\
\hline French Mn Read (TEVL) & 90 & $84.91 \%$ \\
\hline Stopwatch with any text & 9 & $8.49 \%$ \\
\hline $\begin{array}{l}\text { I don't time the patient, but I assess general speed } \\
\text { (quick, slow). }\end{array}$ & 4 & $3.77 \%$ \\
\hline Mr Petit & 2 & $1.89 \%$ \\
\hline Computer test & 1 & $0.94 \%$ \\
\hline \multicolumn{3}{|c|}{ Do you believe your methodology is effective? $N=123$} \\
\hline 1 & 0 & $0.00 \%$ \\
\hline 2 & 5 & $4.03 \%$ \\
\hline 3 & 30 & $24.19 \%$ \\
\hline 4 & 62 & $50.00 \%$ \\
\hline 5 & 23 & $18.55 \%$ \\
\hline 6 & 3 & $2.42 \%$ \\
\hline
\end{tabular}

Table 4: Focus on the characteristics of low vision rehabilitation providers treating AMD patients. Only orthoptists whose AMD patients represent more than $10 \%$ of their low vision patients were considered. Therefore, 123 low vision rehabilitation providers out of 170 were asked to characterize to what extent they believe in the effectiveness of their methodology (range of 1 to $6: 1=$ 'not effective at all', 6 = 'totally effective'.).

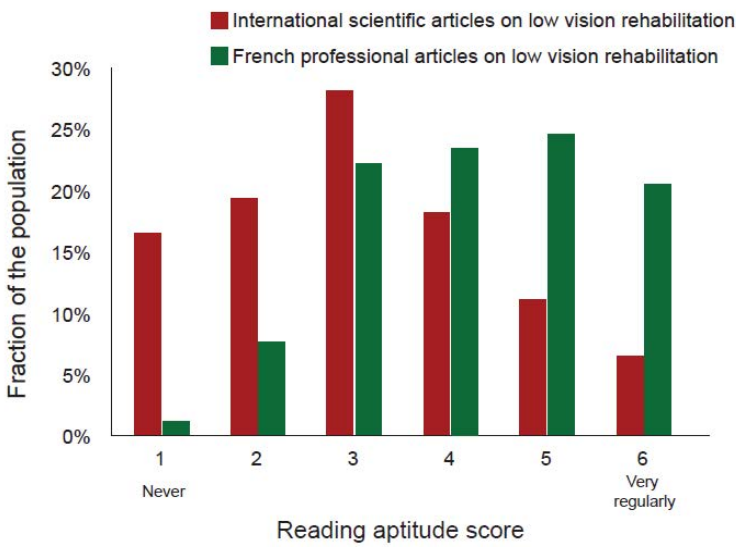

Figure 5: Providers' aptitude to read international scientific articles versus French professional articles on low vision rehabilitation practice. The distribution of responses (with a scale of 1 to $6: 1=$ never reading; $6=$ reading very regularly) shows that a majority $(63 \%)$ of providers do not regularly read international scientific papers on low vision rehabilitation (median score $=3$, with $28.24 \%$ of respondents), whereas they are slightly more apt to read French professional articles (median score $=5$, with $24.71 \%$ of respondents).
Low vision rehabilitation of AMD patients

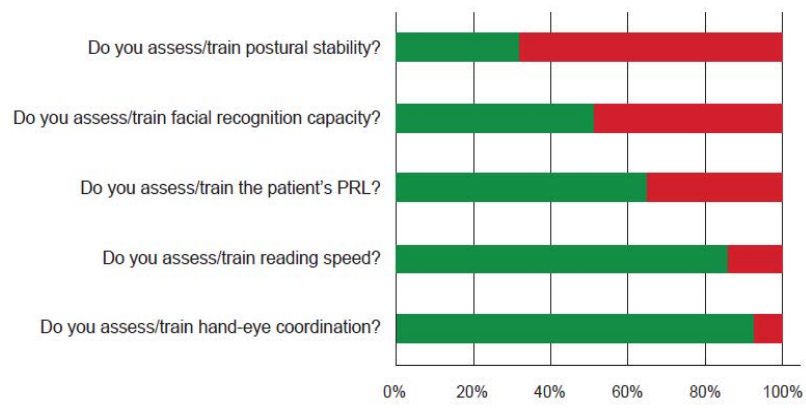

Proportion of 'yes' vs 'no'

Y Yes $\quad$ No

Figure 6: Distribution of AMD patients' functional capabilities trained through low vision re-habilitation. Eye-hand coordination, reading speed, and preferential retinal locus are most often rehabilitated by orthoptists $(92.68 \%$, $86.18 \%$, and $65.04 \%$, respectively), whereas the evaluation others functional capacities such as postural stability is significantly less frequently provided $(32.26 \%)$. 


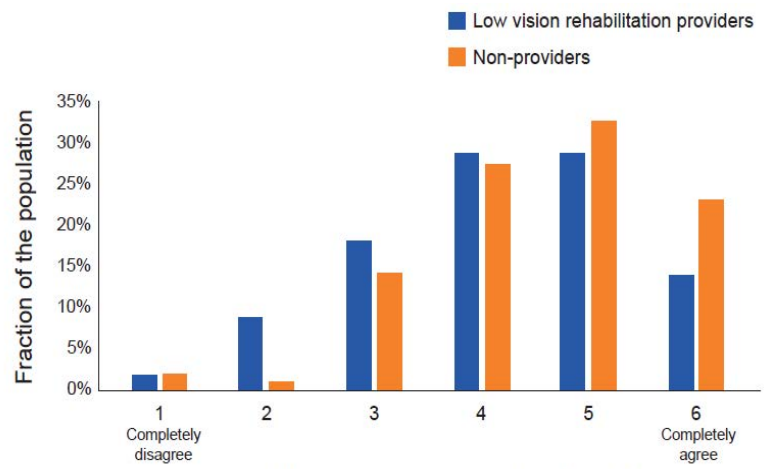

Usefulness score w.r.t. virtual reality tools

Figure 7: Usefulness of VR for low vision rehabilitation of AMD patients. Both low vision rehabilitation providers and non-providers were asked to what extent they were in favor of the use of VR as a low vision rehabilitation tool (scale of 1 to $6: 1=$ completely disagree; $6=$ completely agree). In general, orthoptists (both providers and non-providers) were receptive to this new technology. Differences between groups were not statistically significant. Even when low vision rehabilitation providers reported excellent confidence in their current preferred methodology, differences in willingness between groups remained not significant $(70 \%$ reported a willingness of 4 or more).

$6=$ completely agree) the mean willingness score among orthoptic students was $4.582 \pm 1.1036(\mathrm{n}=110, \min =2 ; \max =6)$, among graduates it was $4.367 \pm 1.2054(n=361 ; \min =1 ; \max =6)$, and for the total sample (both students and graduates) it was $4.417 \pm 1.1847$ ( $\mathrm{n}=471$; $\min =1$; $\max =6$ ).

Differences between groups were not statistically significant. Even when low vision rehabilitation providers reported excellent confidence in their current preferred methodology, differences in willingness between groups remained not significant $(70 \%$ reported a willingness of 4 or more). However, there was a significant difference in the proportion of non-providers and providers who were willing to use VR ( $23.04 \%$ and $14.04 \%$, respectively). No correlation was found between the year of graduation (in both students and graduates) and one's familiarity with VR as a rehabilitation modality $(n=470 ; r=0.084653$; $\mathrm{p}=0.066708$ ). Very few non-providers believed that VR would increase their desire to practice low vision rehabilitation (on a scale of 1 to 6 , mean $3.445 \pm 1.3361 ; n=186$ ).

Among those providers not willing to use VR, we then used openended questions to identify their reservations. The following themes emerged out of the 38 respondents: skepticism regarding its usefulness with older patients $(n=12)$, belief that the equipment is too expensive $(n=7)$, concern that a loss of binocular vision due to a scotoma will prevent the patient from attaining $3 \mathrm{D}$ vision with the HMD $(\mathrm{n}=6)$, assumption that VR does not accurately depict real life $(n=6)$, the practitioner's own lack of confidence in using such technology $(n=4)$, and opinion that this modality is too exhausting for the participant $(\mathrm{n}=2)$. Additional unique responses $(\mathrm{n}=1)$ included: "There are already enough rehabilitation tools"; "The technology has not yet been perfected"; "I am too close to retirement to invest in this tool"; "It's a gadget"; "It does not guarantee a good relationship between the patient and provider"; "We can't see patient's eye when using it"; "I don't think this technology has progressed far enough"; and "It is not suitable for patients with severe visual impairment".

\section{Discussion}

This survey reflects a representative sample of French orthoptists and their current low vision rehabilitation practices. Half of all French orthoptists practice in either Ile de France (greater metropolitan Paris) or Auvergne Rhone Alpes (greater metropolitan Lyon). This demographic is consistent with a corresponding greater population density in these areas. Similarly, there are fewer orthoptists in areas where ophthalmology and medical personnel in general, are in shortage ("medical deserts"). Given that an orthoptist can only provide low vision rehabilitation when prescribed by an ophthalmologist, these medical deserts pose a real concern. Current measures underway to address these issues include possible expansion of orthoptist scope of practice in medical desert areas.

Half of all orthoptists reported lacking confidence in their ability to practice low vision rehabilitation upon graduation due to insufficient training. Almost $40 \%$ of practitioners never practiced low vision rehabilitation before graduation and $45 \%$ of providers chose to pursue this training after graduation. Given that a provider's confidence is correlated with his likelihood of offering low vision rehabilitation, these findings clearly highlight the need to increase university-sponsored internships in this modality. If this is infeasible, other avenues of training must be explored such as continuing education workshops.

Furthermore, courses vary greatly across universities. Training in low vision rehabilitation is not a required component of orthoptic curriculum and it is thus offered at the school's individual discretion. Due to this lack of standardization, patients have no way of knowing whether their provider is trained in low vision rehabilitation. Additional factors limiting the number of practitioners include lack of time or funding to pursue continuing education certification. Consequently, there is a shortage of providers, particularly in rural communities. These deficits highlight the need to standardize low vision rehabilitation training among universities.

In an effort to ameliorate this deficit, in the United States, the Michigan Optometric Association encourages optometrists to complete a low vision rehabilitation certification. However, Carlson and Hinkley (2011) found that while $26 \%$ of providers offer low vision rehabilitation, only $6.4 \%$ of them are actually certified. As in our survey, reasons cited for not obtaining this certification include: low vision care not comprising a significant portion of their practice, lack of support from their current practice environment, no legal requirement to be certified in or-der to offer low vision rehabilitation, insufficient time to become certified, complexity of the certification process, and no direct increase in practice revenues [61]. A 2015 survey of Canadian optometrists reticent to providing low vision rehabilitation similarly cited lack of knowledge, equipment, or experience; that low vision assessment is too time consuming; and that the cost is too prohibitive [62].

In the absence of sufficient incentives to pursue post-graduate low vision rehabilitation certification, we propose alternative avenues. One option might be to increase the length of orthoptic training in France to ensure better training in all orthoptic sub-specialties. Indeed, in France, orthoptists train for only 3 years. Yet, their scope of practice almost nearly approaches that of their colleagues in Canada or the United States who train for 5 years. Given the breadth of study required in an abbreviated course of time, it is difficult to guarantee a high degree of educational quality. Additionally, governing boards could require a national licensing exam, including competence in low vision rehabilitation, for all orthoptists, similar to the national exams required of other professional degrees.

Our survey findings, as well as a review of the literature, reveal there is no gold standard consensus for low vision rehabilitation among 
providers $[2,27,28,62]$. Although half of orthoptists report practicing low vision rehabilitation, only $8 \%$ incorporate this modality in the majority of their AMD treatment plans. Not only do the tools and techniques used in AMD reeducation vary widely from one practitioner to another, but, furthermore, there is no standardization between which functional capacity a practitioner chooses to train (hand-eye coordination, reading speed, facial recognition, postural stability, visual exploration, fixation stability, etc.)

Particularly in rural areas, the majority of low vision rehabilitation therapy is provided by non-specialized orthoptists using an empirical approach or recommendations from colleagues. Even when evidencebased tools exist in the literature, practitioners tend to improvise with their own methods. For example, $85 \%$ of orthoptists measure a patient's reading speed using random text in a book, whereas only $8.49 \%$ employ the MNREAD test that has been validated by strong scientific literature. Similarly, many practitioners still use "pencil and paper" tests to reeducate hand-eye coordination despite a large body of literature demonstrating poor transfer of learning. The tendency of providers to create their own methodologies indicates a lack of accepted protocol in the field, or at least a poor awareness of clinical guidelines. Moreover, the dearth of evidence-based practice within orthoptics and optometry is not limited to France, as many other countries suffer from the same gap in low vision rehabilitation $[2,4,22,25-27,29,31,61-72]$. This extends further into little agreement about how best to measure low-vision rehabilitation outcomes [25].

Finally, this survey explored the feasibility of incorporating virtual reality (VR) techniques in low vision rehabilitation. One such application utilizes wall-mounted screens depicting various city scenes. These are positioned around a visually impaired patient who must then learn to safely cross a street [32]. Similarly, in patients with anisometropic amblyopia, VR head mounted displays have been used in dichoptic training to increase visual and stereoacuity [35]. Although used as an optic aid rather than a rehabilitative tool, eSight is yet another ex-ample of a head-mounted device that enables visually impaired patients to better navigate daily life scenarios by augmenting their perceived environment [73].

The particular advantages of a tool such as VR are many. First, this completely immersive environment can be customized to the individual's progress. For example, for patients hesitant to enter challenging scenarios (i.e., crossing a busy street) the environment can be graded beginning with easier conditions (no traffic) and increasing in complexity (more cars, other pedestrians, cyclists) as the patient gains confidence. This allows the therapist to coach the patient through these psychologically distressing situations [74]. Furthermore, study of this technique by Bowman et al. found a good transfer of learning to the real world. Particularly in older populations, immersive environments have been shown to increase cognitive learning plasticity $[33,40,50]$. Additionally, since the patient knows the exercise is only a simulation, he/she may feel safer and therefore more willing to explore different navigation techniques [74]. This customization further allows the medical provider to transform rehabilitation into a more entertaining and empowering experience for the patient. Finally, unlike video or computer games that require learning how to use the software, VR headsets demand no active manipulation by the patient. Treatment sessions can even be automated so that a therapist need not necessarily be present, thereby increasing cost efficiency and large-scale accessibility.

Given the success of these prior applications, we propose VR could be expanded to rehabilitation of AMD patients. For example, when central vision is lost, one must shift one's visual point of fixation and attention. By simulating real life scenarios with VR, we can then train a patient to best exploit his remaining visual capacities and to discover new visual exploration strategies. Similar to the study described by Bowman et al., as the patient gains comfort in navigating relatively simple simulated environments, he/she would then transition to increasingly complex scenarios, i.e. urban streets with moving pedestrians and vehicles.

In order to standardize and assess the effectiveness of such training, we suggest pre- and post- therapy assessment of visual capabilities. Reading speed and discrimination can be measured with the MNREAD test. This is currently the gold standard in research $[17,67,75,76]$, yet is not often applied in actual clinical practice. However, reading is not the only visual function affected by AMD, and so we further recommend evaluating a patient's hand-eye coordination, steadiness of visual fixation, postural stability (using a force platform), ability to ambulate, and perceived quality of life and autonomy. Although not practical in clinical practice, EEG and brain imaging (such as functional and anatomical magnetic resonance imaging, fMRI and aMRI, respectively), could further be used in research to objectively measure and validate the effectiveness of such training, and to better understand the cognitive impact of this care.

Our study found that a majority of orthoptists would be willing to incorporate virtual reality as a therapeutic tool for AMD patients if studies prove its effectiveness. This is in concordance with a 2017 survey by Keller et al. that used social media posts (Facebook) to solicit public opinion on the use of VR in healthcare [77]. However, within the general population, Keller also found a positive correlation between a person's age and his skepticism of VR's utility. In another study, Schmid et al., found a similar positive correlation among physio and occupational therapists regarding their reservation of VR's utility in stroke rehabilitation [47]. This might be explained by a greater familiarity with VR, and new technology in general, among younger physiotherapists who have gradually integrated this modality into therapy $[41,47,74]$. In our study, we did not find this correlation, perhaps because our sample of older practitioners was underpowered. As new and innovative VR tools emerge, providers must be able to adapt to these advances in technology in order to better serve their patients.

Among practitioners who remain skeptical, one concern is whether VR is suitable for older people and how they will interact with new technology. Additionally, some orthoptists worry that in patients who have binocular vision deficits, such as in AMD, a lack of 3D perception will render a head-mounted device ineffective. However, this is not the case as head-mounted devices exploit a combination of binocular disparity, dynamic stereoscopy, and perspective distortion to generate images. Therefore, even if a patient lacks one of these three facilities, he/she can still compensate by using the other two. In addition, head mounted displays are able to track both head position and rotation (using accelerometers, gyroscopes, and magnetometer sensors), thus guaranteeing excellent visual immersion and precision. Currently, one company (Tobii Pro) offers an advanced option that incorporates an eye tracker to enhance visual simulation. At the moment, this model remains too expensive for general clinical practice, but as more brands further develop this technology, it may enhance the attractiveness of VR head mounted displays as a rehabilitation tool in the future.

Additional concerns voiced by some orthoptists include the quality of peripheral visual fields in a head-mounted VR. They wonder whether peripheral distortion could compromise the re-adaptation ability of a person with central vision loss. We anticipate that any such peripheral distortions will be improved as technology rapidly 
Citation: Raphanel M, Shaughness G, Seiple WH, Arleo A (2018) Current Practice in Low Vision Rehabilitation of Age-related Macular Degeneration and Usefulness of Virtual Reality as a Rehabilitation Tool. Aging Sci 6: 194. doi: 10.4172/2329-8847.1000194

advances in the coming years. Other objections stressed the current (over)use of technology in society, cost, accessibility, and uncertainty of social security reimbursement leading to reluctance to incorporate new technology in healthcare settings, despite the potential clinical benefits. Conversely, those orthoptists who favorably view VR cite that its use may lend greater credibility to the profession by reducing the technological gap between ophthalmologists and orthoptists. We propose that if practitioners could be reassured that these tools will not detract from their own professional expertise and value, and if their fears regarding dependency on the overuse of new technology could be assuaged, they would become more receptive to the adoption of VR.

Of encouragement, most recently graduated orthoptists hail from a younger generation born into the digital world, and who therefore fluently speak the language of technology. As new and innovative VR tools emerge, providers must adapt to these advances in technology in order to best serve their patients. Additionally, as the current population ages, the next generation of older adults will not be technologically naive. These retirees will have become accustomed to using a variety of computerized devices such as smartphones or tablets and they will likely be more willing to try new technological tools in the future.

\section{Conclusion}

Evidence-based practice is poorly employed in the paramedical field, and in particular in low vision rehabilitation. To address this deficit, further studies of current practice methodologies among low vision rehabilitation providers are necessary. A better understanding of the factors contributing to the success or failure of a given rehabilitation technique will enable improvement measures to increase its effectiveness in the future.

The development of an effective, validated, and standardized training protocol for AMD patients that transfers to real-life conditions is an important goal of low vision rehabilitation practice. Currently, AMD rehabilitation mainly focuses on reading speed and discrimination tasks $[17,18,67,75,76,78]$. However, vision loss has consequences on a person's activities of daily living beyond reading difficulties. Changes in postural stability, hand-eye coordination, mobility, autonomy, and perceived quality of life are equal considerations in any successful rehabilitation program.

Active visual exploration strategies using both static and dynamic body movement, as well as hand-eye coordination training (as it can be accomplished using an additional sensor on the patient's hand) made possible by VR may offer AMD patients excellent transfer of learning from simulated scenarios to real-world experiences. Additionally, VR can be tailored to create increasingly dynamic and visually complex environments for the patient to navigate. Improved provider training, using evidence-based protocols as established by the literature, is needed to establish an effective, cost-efficient model for providing standardized low vision rehabilitation to persons diagnosed with AMD. Such a VR program offers the opportunity to thereby create an entertaining, immersive environment that promotes better real-world transfer of learning.

\section{Acknowledgements}

This research was supported by ANR - Essilor Silver Sight Chair ANR-14CHIN-0001 and by the Institute Universities d'Ingénierie en Santé (IUIS) of Sorbonne Université.

\section{Conflict of Interest}

The authors declare no competing interests.

\section{References}

1. Christoforidis JB, Tecce N, Dell'Omo $R$ (2011) Age related macular degeneration and visual disability. Curr Drug Targets 12: 221-233.

2. Hooper P, Jutai JW, Strong G (2008) Age-related macular degeneration and low-vision rehabilitation: a systematic review. Can J Ophthalmol 43: 180-187.

3. Pennington KL, DeAngelis MM (2016) Epidemiology of age-related macular degeneration (AMD): associations with cardiovascular disease phenotypes and lipid factors. Eye Vis 3: 34-54

4. Laliberte Rudman D, Egan MY, McGrath CE (2016) Low Vision Rehabilitation, Age-Related Vision Loss, and Risk: A Critical Interpretive Synthesis. Gerontologist 56: 32-45.

5. Subhi Y, Sørensen TL (2017) Neovascular Age-Related Macular Degeneration in the Very Old ( $\geq 90$ Years): Epidemiology, Adherence to Treatment, and Comparison of Efficacy. J Ophthalmol 2017: e7194927.

6. Lambert NG, Singh MK, EIShelmani H (2016) Risk Factors and Biomarkers of Age-Related Macular Degeneration. Prog Retin Eye Res 54: 64-102.

7. McGrath C, Laliberte Rudman D, Spafford M (2017) The Environmental Production of Disability for Seniors with Age-Related Vision Loss. Can J Aging 36: 55-66.

8. García-Layana A, Cabrera-López F, García-Arumí J (2017) Early and intermediate age-related macular degeneration: update and clinical review. Clin Interv Aging 12: 1579-1587.

9. Mitchell J, Bradley C (2006) Quality of life in age-related macular degeneration: a review of the literature. Health Qual Life Outcomes 4: 97

10. McGuinness MB, Finger RP, Karahalios A (2017) Age-related macular degeneration and mortality: the Melbourne Collaborative Cohort Study. Eye Lond Engl 31: 1345-1357.

11. Desmettre T, Hladiuk K, Bourgois S (2006) «État des lieux » en rééducation orthoptique Basse Vision dans la région Nord-Pas-de-Calais. Fr J Ophthalmol 26: 241-248.

12. Rees G, Mellor D, Holloway EE (2013) Integrated depression management: a proposed trial of a new model of care in a low vision rehabilitation setting. Ophthalmic Epidemiol 20: 321-329.

13. Rovner BW, Casten RJ, Hegel MT (2011) Improving function in age-related macular degeneration: design and methods of a randomized clinical trial. Contemp Clin Trials 32: 196-203.

14. Rovner BW, Casten RJ, Hegel MT (2013) Improving Function in Age-Related Macular Degeneration: A Randomized Clinical Trial. Ophthalmology 120: 16491655

15. Dawson SR, Mallen CD, Gouldstone MB (2014) The prevalence of anxiety and depression in people with age-related macular degeneration: a systematic review of observational study data. BMC Ophthalmol 14: 78.

16. Zheng Y, Wu X, Lin X (2017) The Prevalence of Depression and Depressive Symptoms among Eye Disease Patients: A Systematic Review and Metaanalysis. Sci Rep 7: e46453.

17. Hamade N, Hodge WG, Rakibuz-Zaman M (2016) The Effects of Low-Vision Rehabilitation on Reading Speed and Depression in Age Related Macular Degeneration: A Meta-Analysis. PLoS ONE 11: e0159254.

18. Grant P, Seiple W, Szlyk JP (2011) Effect of depression on actual and perceived effects of reading rehabilitation for people with central vision loss. $J$ Rehabil Res Dev 48: 1101-1108.

19. Hurley SF, Matthews JP, Guymer RH (2006) Cost-effectiveness of smoking cessation to prevent age-related macular degeneration. Cost Eff Resour Alloc CE 2008; 6: 18

20. Stroupe KT, Stelmack JA, Tang XC (2006) Economic Evaluation of Low-Vision Rehabilitation for Veterans With Macular Diseases in the US Department of Veterans Affairs. JAMA Ophthalmol 2018; 136: 524-531.

21. Tamura H, Goto R, Akune Y (2015) The Clinical Effectiveness and CostEffectiveness of Screening for Age-Related Macular Degeneration in Japan: A Markov Modeling Study. PLoS ONE 10: e0133628.

22. Owsley C, McGwin G, Lee PP (2009) Characteristics of Low Vision Rehabilitation Services in the United States. Arch Ophthalmol 127: 681-689. 
Citation: Raphanel M, Shaughness G, Seiple WH, Arleo A (2018) Current Practice in Low Vision Rehabilitation of Age-related Macular Degeneration and Usefulness of Virtual Reality as a Rehabilitation Tool. Aging Sci 6: 194. doi: 10.4172/2329-8847.1000194

23. Haute Autorité de Santé (2012) Principes de la prise en charge de la rééducation de la basse vision.

24. Thite N, Jaggernath J, Chinanayi F (2015) Pattern of optometry practice and range of services in India. Optom Vis Sci 92: 615-622.

25. Binns AM, Bunce C, Dickinson C (2006) How effective is low vision service provision? A systematic review. Surv Ophthalmol 2012; 57: 34-65.

26. Gillespie-Gallery H, Conway ML, Subramanian A (2012) Are rehabilitation services for patients in UK eye clinics adequate? A survey of eye care professionals. Eye (Lond) 26: 1302-1309.

27. Ryan B (2014) Models of low vision care: past, present and future. Clin Exp Optom 97: 209-213.

28. Kammer R, Sell C, Jamara RJ (2009) Survey of optometric low vision rehabilitation training methods for the moderately visually impaired. Optometry 80: $185-192$.

29. Markowitz SN (2016) State-of-the-art: low vision rehabilitation. Can J Ophthalmol 51: 59-66.

30. Gold D, Zuvela B, Hodge WG (2006) Perspectives on low vision service in Canada: a pilot study. Can J Ophthalmol 41: 348-354.

31. Leat SJ (2016) A Proposed Model for Integrated Low-Vision Rehabilitation Services in Canada. Optom Vis Sci 2016; 93: 77-84.

32. Bowman EL, Liu L (2017) Individuals with severely impaired vision can learn useful orientation and mobility skills in virtual streets and can use them to improve real street safety. PloS One 12: e0176534.

33. Molina KI, Ricci NA, de Moraes SA (2014) Virtual reality using games for improving physical functioning in older adults: a systematic review. J Neureeng Rehabil 11: 156

34. Pedroli E, Serino S, Cipresso P (2015) Assessment and rehabilitation of neglect using virtual reality: a systematic review. Front Behav Neurosci 9: 1-15.

35. Žiak P, Holm A, Halička J (2017) Amblyopia treatment of adults with dichoptic training using the virtual reality oculus rift head mounted display: preliminary results. BMC Ophthalmol 17: 1-8.

36. Li L, Yu F, Shi D (2017) Application of virtual reality technology in clinical medicine. Am J Transl Res 9: 3867-3880.

37. Levac D, Glegg SMN, Sveistrup H (2016) A knowledge translation intervention to enhance clinical application of a virtual reality system in stroke rehabilitation. BMC Health Serv Res 16: 557-568.

38. Pedroli E, Padula P, Guala A (2017) A Psychometric Tool for a Virtual Reality Rehabilitation Approach for Dyslexia. Comput Math Methods Med 2017: e7048676.

39. Faria AL, Andrade A, Soares $L$ (2016) Benefits of virtual reality based cognitive rehabilitation through simulated activities of daily living: a randomized controlled trial with stroke patients. J Neuroeng Rehabil 13: 96-108.

40. Levy F, Leboucher P, Rautureau G (2016) Fear of falling: efficacy of virtual reality associated with serious games in elderly people. Neuropsychiatr Dis Treat 12: 877-881.

41. Jerdan SW, Grindle M, van Woerden HC (2006) Head-Mounted Virtual Reality and Mental Health: Critical Review of Current Research. JMIR Serious Games 2018; 6: e14.

42. Navarro-Haro MV, López-del-Hoyo Y, Campos D (2017) Meditation experts try Virtual Reality Mindfulness: A pilot study evaluation of the feasibility and acceptability of Virtual Reality to facilitate mindfulness practice in people attending a Mindfulness conference. PLoS ONE 12: 1-14

43. Pavlou M, Kanegaonkar RG, Swapp D (2012) The effect of virtual reality on visual vertigo symptoms in patients with peripheral vestibular dysfunction: a pilot study. J Vestib Res Equilib Orientat 22: 273-281.

44. Wilson CJ, Soranzo A (2015) The Use of Virtual Reality in Psychology: A Case Study in Visual Perception. Comput Math Methods Med; 2015: 151702.

45. Maples-Keller JL, Bunnell BE, Kim S-J (2017) The use of virtual reality technology in the treatment of anxiety and other psychiatric disorders. Harv Rev Psychiatry 25: 103-113.

46. Pedreira da Fonseca E, Ribeiro da Silva NM, Pinto EB (2017) Therapeutic Effect of Virtual Reality on Post-Stroke Patients: Randomized Clinical Trial. J Stroke Cerebrovasc Dis 26: 94-100.
47. Schmid L, Glässel A, Schuster-Amft C (2016) Therapists' Perspective on Virtual Reality Training in Patients after Stroke: A Qualitative Study Reporting Focus Group Results from Three Hospitals. Stroke Res Treat 2016: e6210508.

48. Riva G, Baños RM, Botella C (2016) Transforming Experience: The Potentia of Augmented Reality and Virtual Reality for Enhancing Personal and Clinical Change. Front Psychiatry 7: 1-14

49. Monge Pereira E, Molina Rueda F, Alguacil Diego IM (2014) Use of virtua reality systems as proprioception method in cerebral palsy: clinical practice guideline. Neurol Barc Spain 29: 550-559.

50. de Bruin ED, Schoene D, Pichierri G (2010) Use of virtual reality technique for the training of motor control in the elderly. Some theoretical considerations. Z Gerontol Geriatr 2010; 43: 229-234.

51. Guze PA (2015) Using Technology to Meet the Challenges of Medical Education. Trans Am Clin Climatol Assoc 126: 260-270.

52. Deutsch J, McCoy SW (2017) Virtual reality and serious games in neurorehabilitation of children and adults: Prevention, plasticity and participation. Pediatr Phys Ther 2017; 29: 23-36.

53. de Gelder B, Kätsyri J, de Borst AW (2018) Virtual reality and the new psychophysics. Br J Psychol 109: 421-426.

54. Parsons TD (2015) Virtual Reality for Enhanced Ecological Validity and Experimental Control in the Clinical, Affective and Social Neurosciences. Front Hum Neurosci 9: 660.

55. Parsons TD, Gaggioli A, Riva G (2017) Virtual Reality for Research in Socia Neuroscience. Brain Sci 7: e42.

56. Laver KE, George S, Thomas S (2015) Virtual reality for stroke rehabilitation Cochrane Database Syst Rev 2: CD008349.

57. Lewis GN, Woods C, Rosie JA (2011) Virtual reality games for rehabilitation of people with stroke: perspectives from the users. Disabil Rehabil Assist Technol 6: 453-463.

58. Threapleton K, Drummond A, Standen P (2016) Virtual rehabilitation: What are the practical barriers for home-based research? Digit Health 2: 1-11.

59. Vignais N, Kulpa R, Brault S (2015) Which technology to investigate visual perception in sport: Video vs. virtual reality. Hum Mov Sci 39: 12-26.

60. Démographie des orthoptistes (2017) Data:Drees études et statistiques.

61. Carlson AM, Hinkley SB (2011) The status of low vision rehabilitation and certification in the state of Michigan. Optometry 82: 697-709.

62. Lam N, Leat SJ, Leung A (2015) Low-vision service provision by optometrists: a Canadian nationwide survey. Optom Vis Sci 92: 365-374.

63. Dickinson C, Linck P, Tudor-Edwards R (2011) A profile of low vision services in England: the Low Vision Service Model Evaluation (LOVSME) project. Eye 25: 829-831.

64. Rowe FJ, Elliott S, Gordon I (2017) A review of Cochrane systematic reviews of interventions relevant to orthoptic practice. Strabismus 25: 1-11.

65. McCabe P, Nason F, Demers Turco P (2000) Evaluating the effectiveness of a vision rehabilitation intervention using an objective and subjective measure of functional performance. Ophthalmic Epidemiol 7: 259-270.

66. Hinds A, Sinclair A, Park J (2003) Impact of an interdisciplinary low vision service on the quality of life of low vision patients. $\mathrm{Br} \mathrm{J}$ Ophthalmol 87: 1391 1396.

67. Chung ST (2011) Improving reading speed for people with central vision loss through perceptual learning. Invest Ophthalmol Vis Sci 52: 1164-1170.

68. Omar R, Knight V, Aziz Mohammed M (2014) Low vision rehabilitation and ocular problems among industrial workers in a developing country. Malays Fam Physician Off J Acad Fam Physicians Malays 9: 27-33.

69. Wilkinson ME, Shahid KS (2017) Low vision rehabilitation: An update. Saudi J Ophthalmol 32: 134-138

70. Agarwal A, Rhoades WR, Hanout M (2015) Management of neovascular agerelated macular degeneration: current state-of-the-art care for optimizing visual outcomes and therapies in development. Clin Ophthalmol 9: 1001-1015.

71. Meyniel C, Bodaghi B, Robert P-Y (2017) Revisiting Vision Rehabilitation. Front Syst Neurosci 11: 1-6. 
Citation: Raphanel M, Shaughness G, Seiple WH, Arleo A (2018) Current Practice in Low Vision Rehabilitation of Age-related Macular Degeneration and Usefulness of Virtual Reality as a Rehabilitation Tool. Aging Sci 6: 194. doi: 10.4172/2329-8847.1000194

Page 13 of 13

72. Harper R, Creer R, Jackson J (2016) Scope of practice of optometrists working in the UK Hospital Eye Service: a national survey. Ophthalmic Physiol Opt J Br Coll Ophthalmic Opt Optom 36: 197-206.

73. Ehrlich JR, Ojeda LV, Wicker D (2017) Head-Mounted Display Technology for Low Vision Rehabilitation and Vision Enhancement. Am J Ophthalmol 176: 26-32.

74. Freeman D, Haselton P, Freeman J (2018) Automated psychological therapy using immersive virtual reality for treatment of fear of heights: a single-blind, parallel-group, randomised controlled trial. Lancet Psychiatry 1: 1-8.

75. Coco-Martín MB, Cuadrado-Asensio R, López-Miguel A (2013) Design and
Evaluation of a Customized Reading Rehabilitation Program for Patients with Age-related Macular Degeneration. Ophthalmology 120: 151-159.

76. Seiple W, Grant P, Szlyk JP (2011) Reading rehabilitation of individuals with AMD: relative effectiveness of training approaches. Invest Ophthalmol Vis Sci 52: $2938-2944$.

77. Keller MS, Park HJ, Cunningham ME (2017) Public Perceptions Regarding Use of Virtual Reality in Health Care: A Social Media Content Analysis Using Facebook. J Med Internet Res 19: e419.

78. Virgili G, Acosta R, Bentley SA (2018) Reading aids for adults with low vision Cochrane Database Syst Rev 4: CD003303.

This article was originally published in a special issue, entitled: "Aging

Challenges in a Digital World", Edited by Dr. Fereshteh Barei, Paris Dauphine University, Paris, France. 